\title{
Integrating ICT in Teacher Colleges - A Change Process
}

\author{
Noga Magen-Nagar and Ditza Maskit \\ Gordon College of Education, Haifa, Israel
}

nogamagen@gmail.com; ditzamaskit@gmail.com

\begin{abstract}
The National Israeli Information and Communication Technology (ICT) Program that called for the "adaption of the educational system to the $21^{\text {st }}$ century", has been implemented in Israel since 2010. The program's purpose intended to introduce an 'ICT culture' in the educational system pre-schools and lower-level schools, as well as in higher education institutions, including teachers colleges. Following this call, the current study is aimed at examining the integration of ICT in a teaching training college in the north of Israel, in the context of a technological-pedagogic setting, the ICT culture in the college, and how educators' metaphorical sensations contribute to their use of ICT tools and to student training in an ICT environment. The second aim of the research was to identify the operating factors in the course of educators' professional development that impact on the integration of advanced technologies in teaching.

This mixed-methods study involved 120 educators. Through structural equation modelling, the findings show that educators' familiarity and mastery of ICT tools influence use for teaching purposes, more so than personal feelings, the ICT culture, and the availability of the tools. Findings emphasize the need for promoting the integration of technology in teachers colleges as a learning organization, from a systemic view, which emphasizes the teacher educator's personalprofessional development.
\end{abstract}

Keywords: ICT integration; educators; innovational change; teacher colleges

\section{Introduction}

The integration of technologies in colleges in the education system in Israel began in the 1980s through the creation of policies and direct funding, which included allocating financial resources and personnel for building infrastructure, equipment, technical services, and ongoing maintenance. During the 1990s, the education system established a national inter-collegial communication center, which provided internet and technical services, and techno-pedagogical support for

Material published as part of this publication, either on-line or in print, is copyrighted by the Informing Science Institute. Permission to make digital or paper copy of part or all of these works for personal or classroom use is granted without fee provided that the copies are not made or distributed for profit or commercial advantage AND that copies 1) bear this notice in full and 2) give the full citation on the first page. It is permissible to abstract these works so long as credit is given. To copy in all other cases or to republish or to post on a server or to redistribute to lists requires specific permission and payment of a fee. Contact Publisher@InformingScience.org to request redistribution permission. the colleges. Following the center's activity, colleges have made changes in the curriculum and included courses for computer and information literacy and professional development for educators (college teachers). Subsequently, the education system encouraged colleges to expand technological inclusion, by differentially increasing their budgets according to the number of ICT courses they provide. This process caused a rap- 
id growth of diverse ICT courses and increased the purchase of technological equipment. However, at the beginning of the $21^{\text {st }}$ century, budget cuts occurred in the education system, causing poor support and a significant decline in the number of ICT courses, so much so that about $70 \%$ of the graduates did not experience any ICT instruction (Goldstein et al., 2011).

In 2010, following ministerial changes in government, a new long-term national ICT program began, called "Adapting the Educational System to the $21^{\text {st }}$ Century". This ICT program encompasses all of the schools in the country and the teachers colleges in the academic colleges for education. ICT training of students (teacher students) has been gradually applied in the teachers colleges over a course of five years, so that each year $20 \%$ of the colleges join the program. The Ministry of Education provides funds for each college for infrastructure improvement, professional development for educators, and development of an ICT curriculum. Additionally, the Ministry provides a budget for the inter-collegial communication center for the continued support of the colleges. During the program, each student is required to study a compulsory course including ICT in teaching ( 2 hours per week) in each of their three years of training; each teacher educator is required to include ICT in the instruction of every course as a model for students. At the end of the studies, the student must successfully pass a qualification test in information technologies and their application in teaching and learning, which is a condition for beginning the internship year (Ministry of Education, 2011).

Generally, the goals of the ICT program are to assimilate an innovative pedagogy and instill $21^{\text {st }}$ century skills in all of the learners within the education system including pupils and teaching students. Mastering $21^{\text {st }}$ century skills prior to entering the workforce is critical. Training teachers with a propensity to use these skills has been defined in Israel as a national and central need and a goal that places a new challenge for the teacher training system, whose interest lies in anchoring the professional training in processes based on implementing the best pedagogy possible in an environment that is based on ICTs. These processes include the following: an educated use of digital teaching-learning processes in a technology-integrated classroom; development of teaching-learning processes that are based on structuring personal and cooperative knowledge; research-based self-learning in combination with innovative technological tools; creation of, and providing accessibility to, digital learning material; management of the teaching-learning processes with online organizational tools; expanding the boundaries of the classroom and effective learning times; and providing response to various learning styles (Ministry of Education, 2013).

Adjusting teachers' training with the above in mind involves processes of change, while taking into consideration all of their consequences. The current research focuses on this issue and examines the processes of change that have occurred in one of the teachers colleges in relation to integration of best-practice pedagogy in an environment that is based on technology, information, and communication.

\section{Theoretical Background}

\section{Teaching in an ICT Environment}

The accelerated development of technology in the world in general has created a new culture, a digital one, in which technologies constitute an inseparable part of a renewed design of the citizen and society from a socio-cultural aspect (Horizon Report, 2014). Indeed, recently, the educational systems are under constant pressure regarding the need to instill changes, mainly in the context of ICTs (Alexander, 2006; Hargreaves \& Fullan, 2013; Martinovic \& Zhang, 2012; Zhang, 2010), and changes that are directed at a new pedagogy which "involves a learning partnership between and among students and teachers with the teacher as a change agent" (Fullan \& Donnelly, 2013, p. 23). 
Innovative and updated pedagogy is based on complex learning behaviors, which require learning in a social and cooperative context, while taking advantage of the potential hidden in technology in the learned field (Bonk, 2010). The literature points out the decisive role teachers play in implementing this new pedagogy in the classroom (Anderson, 2008; Johnson, Levine, Scott, Smith \& Stone, 2009; Kozma, 2010; Linn, 2005). These roles include integration of digital teachinglearning processes, adopting student-focused methods, exposing students to experiences in authentic research processes, development of independent processes of structuring knowledge, and encouragement of cooperative activities between learners (Ertmer \& Ottenbreit-Leftwich, 2010; Ilomaki, 2008; Rizza, 2011). Teachers are expected to use technologies for collecting, managing, creating, and sharing information and exposing students to constructive cooperative learning opportunities (Bower, Hedberg \& Kuswara, 2010; Drexler, Baralt \& Dawson, 2008; Solvie \& Kloek, 2007). In order to achieve such learning, many education systems encourage teachers to expand and improve their learning through ongoing professional development that includes globalisation, mentoring, and re-thinking teacher evaluation methods (Collinson et al., 2009).

Integrating technology in the curriculum and implementing it in class entails a paradigm change in teaching-learning. The magnitude of change in transitioning to ICT teaching is manifested in the use of new hardware and software resources, adopting new teaching-learning practices, and altering the perceptions of all those involved in the change process. This is beneficial, since the new form of pedagogy includes technology, which is attractive to both students and teachers, inspiring them to perform more significant and in-depth work (Fullan, 2007). These processes of change - altering the teaching-learning paradigms in the transition to ICT and changing perceptions of pedagogy - are carried out employing the following stages. First, the "domestication" phase of existing teaching-learning habits (Salomon, 2001), which is characterized by a firstorder change. This involves using a dynamic demonstration beyond the "blackboard and chalk" type, or illustrated and written placards and pictures, and projecting video clips on the subjects studied in class. Later, with the implementation of technology in the teacher's work, we also find use of presentations in order to convey information from different media forms, as well as use of the internet as a supplementary source of information to textbooks. The next stage is a stage in which a second-order change takes place, which manifests itself in adjusting pedagogy to the digital age. This stage, characterized by "The Third Model", is activated by knowledge-structured digital learning communities (Scardamalia \& Bereiter, 1999). These entail the educated use of digital communication between learners, as well as between learners and the teacher, in structuring cooperative knowledge using online cooperative tools, and the regular use of digital information that is accessible to all learners anytime and anywhere.

As a rule, the integration of ICT in the educational system is based mainly on surfing different websites, collecting information, and processing it at a relatively simple level (Hong, Scardamalia, \& Zhang, 2010). Teachers who have had experiences with these processes report that the digital tools used for learning needs transform learning into being more updated, authentic, and relevant to the life of the learner. However, it appears that these perceptions do not lead to the expected pedagogic changes (Voogt, 2012).

As for integrating technology among teaching staff in institutes for higher education, it turns out that effective use of tools, such as Wiki, Moodle, and Google Docs, enable learners to share information details using a variety of textual, visual, and audio media with their peers that require advanced pedagogic and technological knowledge on the teacher's part (Koehler \& Mishra, 2009; MacCallum \& Kinshuk, 2014). Research shows that integrating the technology in institutes for higher education is filled with technical and human obstacles. Educators are not compensated for the investment of resources in preparing ICT courses and their motivation and productivity in implementing the technology decreases (Bates, 2010). We found that little research exists regarding required methods for nurturing the technological, pedagogic, and content knowledge among 
Integrating ICT in Teacher Colleges - A Change Process

educators and students (Tee \& Lee, 2011). Occasionally this process is delayed, and even entails the opposition to adopt technological innovations; the source of this opposition is, at times, ambiguity regarding the contribution to developing processes of cognitive and meta-cognitive thinking (Zeichner \& Barth, 2013). These processes of change are found within the institutes for teacher training, and will be described later on.

\section{Processes of Change in Teachers Colleges in the Digital Age Context}

\section{Processes of change in an educational setting}

Educational systems are always under pressure regarding the necessity for change, renewal, and greater efficacy (Muijs \& Lindsay, 2008; Pij1, 2009). Changes deriving from internal initiatives are based on free choice and the need for cooperation. They are characterized by positive reactions to change among teachers, a strong teacher input, good pedagogy, teachers' responsibility and an obligation to implement the change, professional progress, and greater awareness of methods for improvement (Desimone, 2009). Research indicates that the integration of changes and their implementation involves considerable difficulty, especially in cases where decisions to adopt such changes are not made by those who are intended to implement them (Maskit, 2013).

Studies also indicate that knowledge and understanding of what it is that needs to be changed, motivation, engagement and commitment to the change, and self-regulation of the change process serve as necessary conditions for a conceptual change. Furthermore, an intentional conceptual change becomes possible when a person understands the reasons for the change and when (s)he is supported to plan the change processes, while monitoring and evaluating those processes (Luque, 2003). The teacher's willingness to be an active part in the change process is also mentioned as the prime instigator of real and radical change throughout the educational system (Bransford, Darling-Hammond \& LePage, 2005; Fullan, 2007; Guskey, 2002; Van Veen \& Sleegers, 2006). It has been noted that teachers have an important place and a significant role in the implementation of pedagogical change processes with regard to their knowledge, experience. and expertise, in addition to their professional work and personality (Maskit, 2013). Specific causes that underlie pedagogical changes include dissatisfaction with the existing system of teaching, learning, and assessment; the necessity to raise and improve student achievement levels; teachers' professional need for change; new requirements resulting in discrepancies between educational values and outcomes; the need to absorb new resources; the need to establish a balance among colleagues; as well as the need to integrate other systems into those in which change has already been implemented (Maskit, 2013; Russell, Jane \& Marshall, 2011). Saying that, there is a need to echo teachers' attitudes toward the change process, as well as teachers' practices while implementing change, as important factors in the implementation of change. The current research attends to these notions.

\section{Processes of change with regard to the digital age}

In recent years, the teacher education system has been forced to face the new challenge of instilling a digital culture into teachers colleges. An extensive study performed in 31 OECD countries, which focused on assimilating ICT policy in teachers colleges, emphasized the absence of clarity in relation to ICT policy. The study found that there is a need to create a holistic and cohesive national and international framework for both the general ICT program and the ICT-discipline programs within teachers colleges, and recommended that a culture of research and innovation be encouraged in the colleges. In addition, there is a need to examine ICT policy in relation to curriculum development, teaching skills, and evaluation of frameworks and teaching methods (Rizza, 2011). 
Adopting ICT in the training frameworks entails the implementation of processes of widespread pedagogic and organizational change in the instruction of courses and in academic learning (Amirault, 2012). Research in the field has taught us that the teaching staff in institutions for higher education are surprised and sometimes even against incorporating technological methods of teaching in their work. Vagueness regarding the contribution of innovative technological means to cognitive processes is a main reason for this (Zeichner \& Barth, 2013). The importance of additional factors in relation to the advancement of the integration of technologies in colleges has also been demonstrated, such as the insertion of systemic programs in colleges (Kimble, 1999), developing teaching staff with regard to the plan of change (Jacobsen \& Lock, 2004), accessibility to infrastructures and to resources (Surry, 2001), technical and managerial support throughout the change (Mckenzie, Kirby \& Mims, 1996), focus on concrete lesson demonstrations (Barron \& Goldman, 1994), and developing a positive attitude (Mumtaz, 2000).

An additional study (Granston, 2004) presents a general framework of factors that needs to be included in the integration of technology in teachers colleges. The first factors in this framework include four environmental conditions critical for advancing the integration of technology: an involvement program, staff development, resources/accessibility/infrastructure, and technical and managerial support. Additional factors that influence the course of integrating technology in teaching include being a teaching role model, a positive attitude, training, and the experiential/practical field. In order to ensure that teacher educators will indeed implement technology in their teaching, it is crucial to integrate all factors, and ensure teacher educators have the digital literacy skills required to integrate technology into their teaching. This model emphasizes the coordination and cooperation between interested parties in the organization, starting at the input level and ending at the level of results.

Alongside these studies, which indicate an entirety of factors that are required for the change process, there are still gaps that exist in reality between the central role that is attributed to ICT as a catalyst for innovation in teacher training, including the resources invested in the need for adopting these technologies, and the extent of the adoption of the technology in practice. Therefore, the study also focuses on the reasons preventing educators from training teachers to integrate technology innovatively, despite the availability and accessibility to technological tools and means (Zeichner \& Barth, 2013). Indeed, the study's findings show that ICT teaching in institutions for higher learning is full of technical and human obstacles. Educators are not compensated for their investment and time spent preparing lessons, therefore, their motivation and productivity in implementing technology decreases (Bates, 2010). An additional reason preventing educators from implementing technologies stems from the little existing research on the required methods for the integration of technological knowledge with pedagogic and content-related knowledge among educators and students (Tee \& Lee, 2011).

If a process of integration of technology in teaching takes place in teachers colleges, it is executed through instruction of educators in centers that are designated for developing and improving teaching and learning (Reeves \& Reeves, 2012) and by means of assistance in preparing courses that implement effective ICT (Zeichner \& Barth, 2013). ICT teaching in teacher training takes place within the context of the world of learners. Its planning entails considerations regarding integrating fields of wisdom with the new technological tools and careful planning of these tools' methods of use. Furthermore, the extent of cooperation required in order to successfully achieve the objectives of the course and its assignments is also kept in mind (Bower et al., 2010). The National ICT Program in Israel, which is focused on this organizational and pedagogical change, aims to mold the teachers colleges into learner organizations integrating ICT in the most optimal way possible, by implementing social and digital teaching-learning as part of today's educational culture. This is order to train teachers in all stages of their professional development to teach in a digital age and make them proficient in a complex and quickly-changing digital environment. In 
Integrating ICT in Teacher Colleges - A Change Process

Israel, there are two prominent models in the transition to ICT teaching: a basic course model in the field of ICT, such as information management and digital literacy, and a model for educational and disciplinary specialization courses that are ICT-integrated (Ministry of Education, 2011). From a comprehensive study conducted in four institutes for teacher training in Israel as part of the national ICT program, a slow expansion of the circle of educators that integrate ICT in their work was found (Goldstein et al., 2011). This finding strengthens the need to continue to examine the main factors that are considered in educators' eyes as influencing the adoption of the instruction technologies of teacher trainers and teachers with advanced degrees. The current research is focused on these aspects.

\section{The Use of Metaphors in Teacher Education}

As we frame the above goals, we propose the use of metaphors as an additional perspective with which we can examine teachers' orientations on the introduction of the ICT program. The use of examining teachers' orientations, beliefs, and attitudes through metaphors is well discussed in the literature. Lakoff and Johnson (1980) noted that "most of our ordinary conceptual system is metaphorical in nature" (p. 5) and defined metaphors as "understanding and experiencing one kind of thing in terms of another" (p. 5). Metaphors have a coherence and internal consistency, which provide insights into ideas that are not explicit or consciously held. Concerning educational contexts, it was noted that the examination of alternative metaphors help teachers examine their own assumptions (Connelly, Clandinin, \& He, 1997). Another study analyzing the metaphorical conceptions of learning based on the reflections of 50 participants indicates that the majority of experienced teachers share traditional metaphors portraying teaching and learning as a transmission of knowledge, while a smaller group of teachers expressed constructivist metaphors. The result of the study suggests that metaphors should serve as stepping-stones to broader and more profound conceptions of the nature of teaching and learning (Martinez, Sauleda, \& Huber, 2001). Similarly, more research indicates that metaphors play an essential role in conceptualizing and reflecting upon the nature of teaching and learning, and that metaphor construction is a valuable activity for understanding teachers' practical knowledge. Other conclusions suggest that metaphors may be useful for assisting students understand themselves as teachers and for relating this understanding to their own practice (Leavy, McSorley, \& Boté, 2007). One study suggests that teacher/educator metaphor analysis may be used as a means for examining teachers' values, beliefs, and philosophies about teaching and learning, and that metaphors provide a powerful cognitive tool in gaining insight into prospective teachers' professional thinking (Sabana, Kocbekerb, \& Sabanc, 2007). In summation, it can be said that the use of metaphors can serve as a tool in educational environments for exploring students' and teachers' views and attitudes, as well as known and hidden perceptions with regard to teaching and learning processes. Precisely for this reason, in the current study, we chose to use metaphors as a tool for the examination of the research aims.

\section{The Research Context}

The current research is a case study of one college for teacher training, which trains 1,500 students and practicing teachers in the Master's degree track. The college joined the national ICT program in 2014 and made it its goal to train leading students and teachers by integrating advanced technology in teaching. All educators were invited to join the program, but during the first stages only $15 \%$ of them joined the professional development process. This year, a sharp increase was seen in the resources directed towards the technological field, such as an increase in the number of courses offered to students engaged in remote learning using advanced technology tools (about 20 online courses a year), development of teacher educators via instruction and designated courses, and acquisition of advanced technology (iPads, 3D printers, and a classroom designed for learning using technology). The research was conducted at the beginning of 2015, and its importance lies in an in-depth analysis of the factors involved in integrating ICT in the college 
for education, which invests in advanced and expensive technological resources and in a rich and varied professional development program for educators.

\section{The Aim of the Research}

The aim of the research is focused on the mapping of the factors involved in the process of inserting ICT in one of the teachers colleges in Israel and in identifying the operating factors (encouraging and inhibiting) in the integration process of advanced technologies in teaching.

\section{The research questions}

The research is focused on the following two questions:

1. To what extent does availability of, and support for, technology and pedagogy, the ICT culture in the college, and the metaphoric sensations of educators contribute to the use of ICT tools and to the guidance provided to students in an ICT environment?

2. Which operating factors do educators regard as encouraging or inhibiting in the implementation process of advanced teaching technologies?

\section{Method}

The research is based on one case that was explored in depth, from which it is possible to deduce and learn about the phenomenon as a whole (Stake, 2006). The research method is mixed, and it includes a quantitative component, which addresses the first research question, and a qualitative component, which addresses the second research question. The qualitative research has exposed the internal factors, which are mostly hidden from the quantitative research (Frank, 1998). Thus, the combination of both methods contributes to a deeper and more meaningful understanding from which to examine the perceptions of educators regarding application of advanced technologies in instruction (Eckert, 2013).

The integration of ICT in teachers colleges in accordance with the national ICT program is new for the college. Due to its educational importance, there is an urgent need to investigate several facets of the change's implementation, as stated before. The proposed research was planned as a pilot study, in which a preliminary examination of the phenomenon is conducted while attempting to formulate research hypotheses.

\section{Participants}

The participants in this research are 120 educators out of 200 educators that teach at the college for education, which joined the national ICT program in 2014. Educators have an average of around 7 years of seniority in teaching $(\mathrm{M}=7.25, \mathrm{SD}=6.67)$, around half of them $(43 \%)$ work parttime (up to half time) and around half (57\%) work full time. $85 \%$ of the educators are female and the rest are male.

\section{Research Tools}

This research used a questionnaire that was developed especially for the needs of the current research. The questionnaire is based on one developed for college teachers in Israel (Goldstein et al., 2011) and includes a quantitative component and a qualitative component, as will be explained in detail later. The quantitative component includes the following 5 sets of questions within the questionnaire:

1. The $1^{\text {st }}$ set: A set of questions on the use of ICT tools, which tests the level of use of ICT tools, such as a word processor, internet websites and blogs. The set of questions includes 
ten items on a 5-point Likert scale ranging from "not at all" (1) to "to a very great extent" (5). The reliability of the questions in the current research is $\alpha=.81$. A factor analysis of the questions produced two dimensions: Assimilation, which includes six items and describes the extent to which ICT tools for management and collecting personal information are used, such as "use of a spreadsheet", and Transformation, which includes four items and describes the extent to which cooperative ICT tools are used for structuring knowledge, such as "use of Facebook".

2. The $2^{\text {nd }}$ set: Questions on student training, which examine the extent to which students are guided in ICT assignments in courses, such as use of virtualization, using digital tools to support problem-solving and online discussions. The set of questions includes 18 items on a 5-point Likert scale ranging from "not at all" (1) to "to a very great extent" (5). The reliability of the questions is $\alpha=.91$. A factor analysis produced three dimensions: "Innovative learning strategies", which includes eight items and describes the extent to which advanced strategies for achieving learning goals are used, such as "performing cooperative tasks in an ICT environment"; "technological tools", which include seven items and describes the use of online technological and personal tools for teaching-learning needs, such as "using virtualization, applications, or online games"; and "Online learning environment", which includes three items and describes the use of a learning environment that is based on online cooperation, such as "creating entries or editing concepts and/or activities in a Wiki".

3. The $3^{\text {rd }}$ set: A set of questions on technological-pedagogic availability and support that examines the level of availability and technological-pedagogic support at the college, such as availability of computers for students and educators and cooperation between educators. The set of questions includes eight items, such as "the computer is available for my continuous work", on a scale of six levels, ranging from "I do not know" (1) to "to a very great extent" (5). The reliability of the set of questions is $\alpha=.75$.

4. The $4^{\text {th }}$ set: A set of questions on metaphorical sensations, which examines the participants' level of identification with the metaphors associated with the integration process of innovative technologies. The set includes five items, such as "when I implement innovative technologies during my instruction I feel like a sardine (little fish in the big ocean)". The participants' level of identification with metaphors is measured on a 5-point Likert scale ranging from "not at all" (1) to "to a very great extent" (5). The set's reliability is $\alpha=.64$.

5. The $5^{\text {th }}$ set: An additional question focuses on the ICT culture at the college and examines, on a 5-point Likert scale ranging from "not at all" (1) to "to a very great extent" (5), the extent to which ICT is reflected in the college's culture.

The qualitative component of the questionnaire includes four open-ended questions:

1. What are the reasons that motivate you to implement innovative technologies in the teaching processes?

2. What are the reasons that prevent you from implementing?

3. What are the factors that help you implement?

4. What are the factors that delay your integration?

In addition, demographic data was collected including gender, education, and years of experience seniority as educators at the college. 


\section{Procedure}

The research data was collected at the end of the 2014 academic year. All of the educators at the college were asked to fill out the online questionnaire in their free time, online. The aim of the research was explained to the educators at the start of the questionnaire, and processes to ensure anonymity and privacy were explained. The time it took to fill out the questionnaire was around 30 minutes. All ethical guidelines were followed. Around $60 \%$ of all the teacher educators completed the questionnaire.

\section{Findings}

\section{The Integration of ICT in Teaching}

Following are the descriptive findings, which indicate great variance in the integration of the technologies in teaching. The findings presented are an accumulated percent based on the Likert scale reports of "to a great extent" (4) and "to a very great extent" (5). Choosing these indices indicates positive and deeply significant assertions regarding the implementation of technology in teaching.

On a measure of the use of ICT tools on a sub-measure of assimilation - management and data collection - it was found that most of the educators use a word processor $(81.7 \%)$ and presentations (85\%). About half of the educators (58.3\%) use media websites and only a fifth of the educators use cooperative environments, such as Google Docs (20.8\%). On a sub-measure of transformation - structuring of cooperative knowledge - it was found that educators use synchronous environments, such as Skype (17.5\%), and wikis (10\%).

On a measure of student training in an ICT environment on a sub-measure of strategies for innovative learning, it was found that around half of the educators use research strategies in student training (46.7\%) and in presenting digital products $(43.3 \%)$, and some of the educators use learning strategies that are based on projects (20\%), authentic problem-solving (19.1\%), cooperative online tasks (17.5\%), and event analysis (16.7\%). In the sub-measure of technological tools it was found that around one-third of the educators instruct their students to use video (28.3\%), but only a small number of them instruct their students to use virtualizations, applications, and online games $(16.7 \%)$, and a very small number of educators instruct the students to use a tool for mapping concepts $(5.8 \%)$, a social website $(6.7 \%)$, or a cellular phone $(7.5 \%)$. In the sub-measure of learning environments that is based on online cooperation it was found that most of the educators instruct their students to conduct their learning in Moodle (74.2\%).

In the measure of technological-pedagogic support, it was found that most of the educators testify to the existence of workshops in the college intended for improving their digital literacy $(80.6 \%)$, to the computers being available for their work (74.2\%), and to the existence of technical support $(70.7 \%)$. Around half of the educators testify that there is support for integrating technology into their teaching $(55.8 \%)$, that the computers are available for students $(42.5 \%)$, and that the ICT staff are supportive and encouraging (47.5\%). Around one-third of the educators report that the computer classroom is available when required (33.4\%), and that there is peer learning among the educators $(27 \%)$.

The use of metaphors, as was aforementioned, is intended to serve as an additional viewpoint through which teacher orientations concerning the introduction of the ICT program could be examined. The findings were as follows. Most of the educators $(81.7 \%)$ feel that while implementing innovative technologies, they are like "sardines trapped in a tin", metaphorically referring to the sense of feeling small and having no strength to handle the change. Many others $(71.1 \%)$ stated that they feel like "a fish caught in a net", metaphorically referring to having no strength to 
Integrating ICT in Teacher Colleges - A Change Process

handle the change, nor the power of choosing their own method of action in class. Many educators $(65.8 \%)$ stated that they feel like "a fish in an aquarium", conveying that they are not free to choose whether they can implement the change or not. However, several of the educators $(30.8 \%)$ stated that they feel "like a fish in water", assuring that they are comfortable, "at home", referring to the fact that they know what needs to be done throughout the change as well as how to handle it. Around a third of the educators $(29.2 \%)$ stated that they "feel like a whale" while implementing innovative technologies, referring metaphorically to feeling empowered thanks to knowing exactly how to implement the change.

In the item regarding the ICT culture in the college it was found that around half of the educators $(47.7 \%)$ testify to the fact that ICT is reflected in the college culture.

The first research question focuses on the extent to which technological-pedagogic technical availability and support, the ICT culture in the college, and the metaphoric sensations of the educators contribute to the use of ICT tools and to the guidance of students in an ICT environment.

In order to answer this question, Pearson correlations were calculated between the technologicalpedagogic availability and support, the ICT environment, the educators' metaphoric sensations, use of ICT tools at the level of assimilation and transformation, and student training according to three aspects: strategies for innovative learning, technological tools and an online learning environment (Table 1).

Table 1: Correlation Matrix according to Pearson between the research's variables

\begin{tabular}{|c|c|c|c|c|c|c|c|c|c|}
\hline \multirow{2}{*}{$\begin{array}{l}\text { THE VARIABLES } \\
\text { SUB-VARIABLES }\end{array}$} & \multicolumn{2}{|c|}{$\begin{array}{l}\text { USE OF ICT } \\
\text { TOOLS }\end{array}$} & \multicolumn{3}{|c|}{ STUDENT TRAINING } & \multirow[b]{2}{*}{ 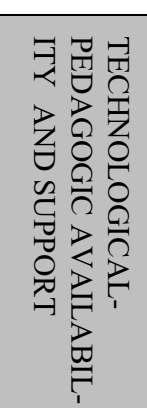 } & \multirow[b]{2}{*}{ 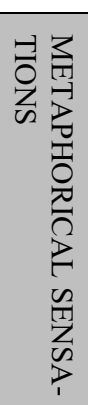 } & \multirow[b]{2}{*}{ M } & \multirow[b]{2}{*}{ SD } \\
\hline & 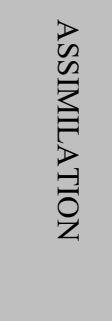 & 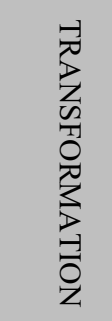 & 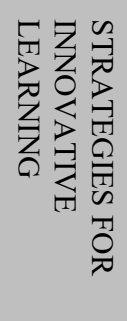 & 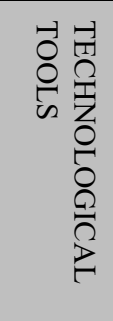 & 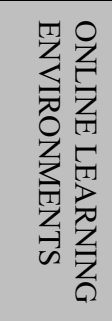 & & & & \\
\hline Assimilation & & & & & & & & 3.23 & 0.8 \\
\hline Transformation & $0.54 * *$ & & & & & & & 1.91 & 0.9 \\
\hline $\begin{array}{l}\text { Strategies for Innova- } \\
\text { tive Learning }\end{array}$ & $0.53^{* *}$ & $0.48^{* *}$ & & & & & & 2.51 & 0.97 \\
\hline Technological Tools & $0.58^{* * *}$ & $0.58^{* *}$ & $0.72 * *$ & & & & & 1.73 & 0.73 \\
\hline $\begin{array}{l}\text { Online Learning Envi- } \\
\text { ronments }\end{array}$ & $0.34 * *$ & $0.47 * *$ & $0.57 * *$ & $0.53 * *$ & & & & 2.36 & 0.75 \\
\hline $\begin{array}{l}\text { Technological- } \\
\text { Pedagogic Availability } \\
\text { and Support }\end{array}$ & $0.22 *$ & $0.29 * *$ & $0.34^{* *}$ & $0.30 * *$ & $0.35^{* *}$ & & & 3.02 & 1 \\
\hline $\begin{array}{l}\text { Metaphorical Sensa- } \\
\text { tions }\end{array}$ & $0.21^{*}$ & $0.23 * *$ & $0.39^{* *}$ & $0.32 * *$ & $0.28 * *$ & 0.03 & & 3.51 & 0.66 \\
\hline ICT Culture & $0.19^{*}$ & $0.27 * *$ & $0.27 * *$ & $0.19 *$ & $0.27 * *$ & $0.37 * *$ & 0.13 & 3.58 & 0.88 \\
\hline
\end{tabular}

Table 1 indicates that there are positive and significant relations, of medium to strong intensity, between most of the research variables. Particularly, it was found that the higher the index for technological-pedagogic availability and support, ICT environment in the college, and educators' metaphoric sensations, the greater was the use of ICT tools (implementation and transformation), student training toward innovative learning, and the use of diverse advanced technological means (including searching for external sources of information/support). The same was found for vice versa. Additionally, there were positive and significant relations between the use of ICT tools at 
the level of assimilation and use of ICT tools on the transformation level. The same can be said about the components of student training, which include strategies for innovative learning, technological tools and an online learning environment.

In order to examine the contribution of technological-pedagogic availability and support, the ICT environment, and educators' metaphoric sensations to the level of use of ICT tools and the level of student training in a ICT environment, a path analysis was conducted with the help of Structural Equation Modeling (SEM), using the statistical program AMOS 18.0 (Analysis of Moment Structures) (Arbuckle, 2009, Blunch, 2008). This analysis is a multi-variable analysis in a graphic environment that is used when examining a complex model that contains a variety of variables or a variety of dependencies between the variables (Byrne, 2010).

The SEM model consists of two components: the measurement model and the structural model. From a methodological viewpoint, it expresses the necessary integration of all research as such. It is based on two characteristics of the definitions of the variables: the first is the operator (the measurement model) and the other, the concept (structural model) (Hoyle \& Panter, 1995). When the measurement and the structural elements integrate into one step, the result is a comprehensive statistical model that can be used to assess the relationship between variables that are free from measurement error (Hoyle, 1995).

The measurement model classifies the factorial component of the latent variables in terms of anticipated and measured variables. The model which is based on calculating the correlation matrix between the measured variables reflects the convergence-discriminative validity of the measured variables. If the correlations between items that specify the same latent factor are higher than the correlations between items that indicate other factors in the model, then the measurement model has construct validity. The construct validity is involved with linking the measurement model to the general theoretical framework, in order to determine whether the model is related to the theoretical concepts and assumptions used, and this is the structural model. The structural model classifies the relationships and effects between the latent variables. The relationship effects between the latent variables are expressed as regression coefficient $(\beta)$, and joint covariance (Byrne, 2010).

The results of the measurement model show that the value of $\chi^{2}$ is $18.26(\mathrm{df}=15)$, and is not statistically significant ( $\mathrm{p}=.249)$. The RMSEA (Root Mean Square Error of Approximation) measure (.042) is lower than .05. The NFI (Normed Fit Index) measure (.944) and the CFI (Comparative Fit Index) measure (0.989) are very high and close to 1 . These findings indicate a model that is very good and that matches the research data.

In a factor analysis of the section 'use of ICT tools', the analysis shows that the latent variable 'use of ICT tools' is divided into two factors: The observed 'assimilation' and 'transformation' factors have high standardized loading coefficients of $\lambda=.73$ and $\lambda=.74$ respectively. An additional factor analysis shows that the latent variable 'student training' divides into three factors: The observed factors 'strategies for innovative learning' and 'online learning environments' have very high standardized loading coefficients of $\lambda=.84$. The 'Technological tools' factor has a high loading coefficient of $\lambda=.65$.

In summary, the results of the measurement model indicate that the research questionnaire has strong validity.

During the second stage an evaluation was conducted for the structural model, which categorizes the influences between the factors, shown in Figure 1. 


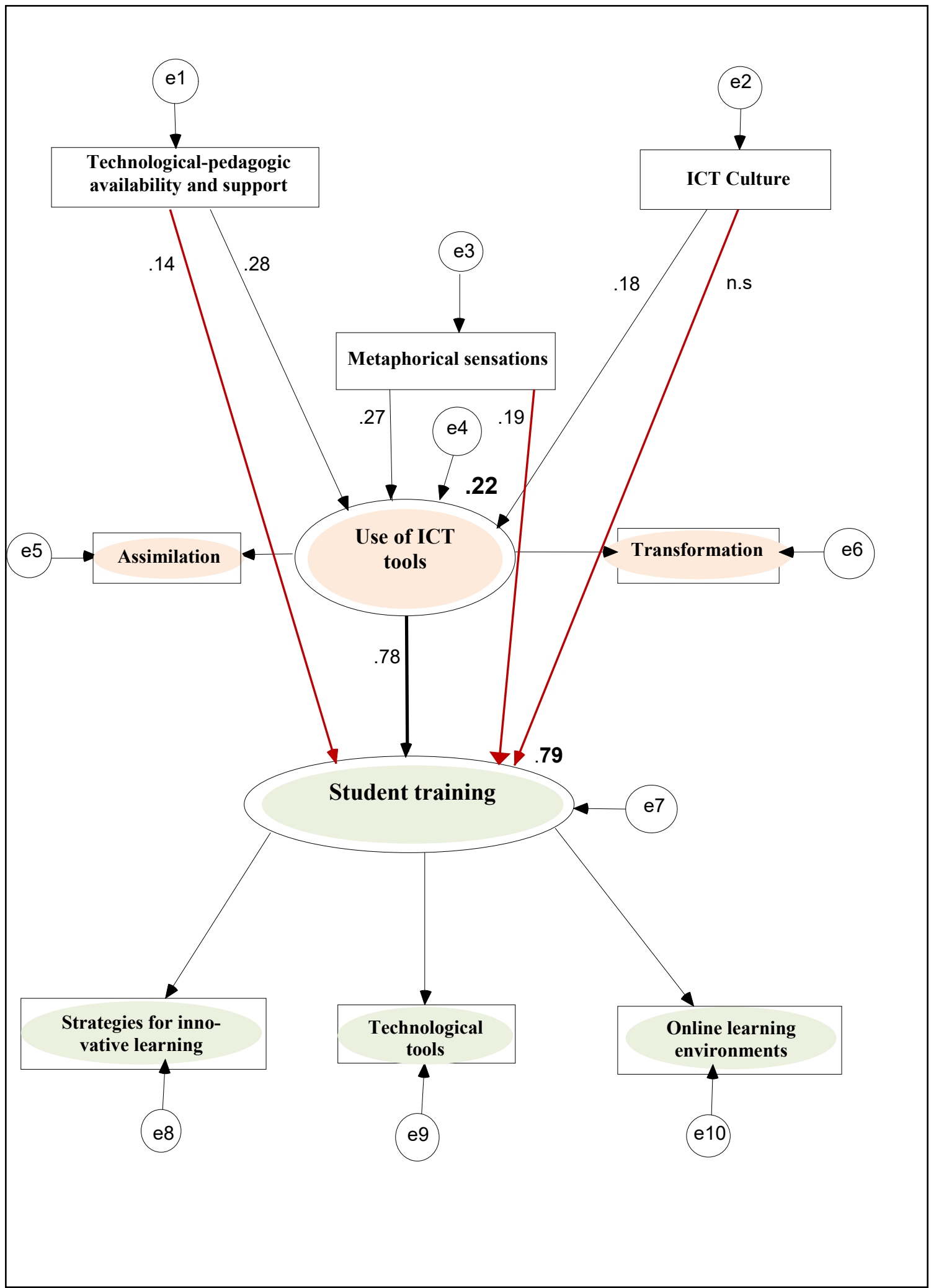

Figure 1: Path Analysis Results - Ways of student training 
From the path analysis, which is presented in Figure 1, the following findings arise:

1. Technological-pedagogic availability and support, the ICT environment, and the educators' metaphoric sensations together explain around one-fifth of the explained variance of use of ICT tools $\left(\mathrm{R}^{2}=.22\right)$. In addition, together, they explain more than three-quarters of the explained variance in the methods of teaching the students $\left(\mathrm{R}^{2}=.79\right)$. The factors that were included in the model therefore explain in a very good way each of the components of student training in an innovative learning environment.

2. The variable 'technological-pedagogic availability and support' in the college has significant positive influences on educators' use of ICT tools $\left(\beta=.28^{* *}\right)$, and on student training $\left(\beta=.14^{*}\right)$. The technological-pedagogic availability and support that is given to educators influence their use of ICT tools to a greater extent than the influence of student training in an ICT environment.

3. The variable 'ICT culture' at the college has a positive influence, significant only regarding educators' use of ICT tools $\left(\beta=.18^{*}\right)$. That is to say, the ICT culture at the college influences educators' use of ICT tools to a relatively small extent, however, it does not influence student training in an ICT environment.

4. The variable 'metaphoric sensations' of educators in an ICT environment has positive and significant influences on the use of ICT tools and in student training. The higher intensity is the influence on the level of use of ICT tools $\left(\beta=.27^{* *}\right)$, and afterwards on the level of student training $\left(\beta=.19^{*}\right)$. In other words, educators' feelings in an ICT environment influence their use of ICT tools to a great extent and influence their instruction of students to a small extent.

5. The variable 'use of ICT tools' has a positive influence, is significant and powerful on student training $\left(\beta=.78^{* * *}\right)$. That is to say, educators' extensive use of a variety of ICT tools greatly influences student training on three levels: Strategies for innovative learning use of technological tools and online learning environments.

6. From the SEM analysis the variables' indirect influences in comparison to their direct influences in the model can also be seen, in the following ways:

a. Student training in an ICT environment was found to be influenced by technological-pedagogic availability and support by means of the use of ICT tools, in a comprehensive and indirect way, more than directly $\left(\beta=.28^{* *}\right.$ and $\beta=.14^{*}$, respectively). From here it can be said that the influence of educators' use of ICT tools is more prominent and significant for student training than the influence of technological-pedagogic availability and support in the college.

b. It was found that student training in an ICT environment is influenced by the ICT culture in an indirect and less powerful way through use of ICT tools, more than it is influenced directly ( $\beta=.18^{*}$ and $\beta=.03$, respectively). From here it can be said that the influence of educators' use of ICT tools is more prominent and significant for student training than the influence of the ICT culture in the college.

c. It was found that student training in an ICT environment is indirectly influenced by metaphoric sensations and, to a lesser extent, by the use of ICT tools, more than being influenced directly ( $\beta=.27^{*}$ and $\beta=.19$, accordingly). From this, it can be stated that the influence of educators' use of ICT tools stands out and is more significant for student training than the influence of their own personal feelings. 
Integrating ICT in Teacher Colleges - A Change Process

In summary, the SEM analysis with the structural-path analysis suggests that the variable "use of ICT tools' serves as a direct and significant factor in each and every one of the components of student training and at the same time it serves as a central mediating factor for the availability and support and the college's ICT culture, together with personal sensations.

\section{The Operating Factors in the Integration Process of Advanced Technology in Instruction}

The second research question examines what the operating (encouraging and inhibiting) factors in the integration process of advanced technology in instruction are, as identified by educators. The analysis of the responses to the open-ended set of questions was performed using the categoricalcontent analysis (Strauss \& Corbin, 1990). The analysis includes three main stages: 1. Open Coding: repeating themes which can be characterized; 2 . Axial Coding: re-mapping of the findings by each category's axis, and making connections between the categories; 3 . Selective Coding: expanding the categories and finding additional anchoring to their existence. In the data analysis, six core categories were identified, through which we can explain educators' perceptions about applying advanced technologies in instruction. Following are the presentation of each category, together with examples taken from educators' own words, as they were written in their responses to the open-ended questions.

\section{A. Appropriate resources}

Educators are sure that the college, as an organized institution, needs to invest resources such as advanced technological equipment, building infrastructure, and provision of technical support. It appears that there is a strong feeling in the college that technological resources are available and it is substantial, as one of them wrote, "This is a trivial question, this is the available tool". In actual fact, many educators report that there are technical difficulties that disrupt the learning process. They encounter technical issues when operating the computers and projectors in the classrooms, there are a lack of classrooms containing interactive whiteboards and a lack of computer rooms, power failures and disconnection from the internet occur, they encounter technical issues with preparing the lessons beforehand, and student have difficulties with the ICT environments. Sometimes, circumstantial constraints occur, causing the number of iPads to be limited, while in fact, at the same time, it is demanded that they be used to teach with. One teacher educator described an additional difficulty. "In the classrooms there is one computer, it is impossible to give a task using technology." Another teacher educator added that there "... is no option of using the computers in the regular classrooms unless the students bring laptops with them, and not everyone brings them". Educators also brought up difficulties that create insecurity and fears in them because in their classroom the technological and accompanying infrastructure do not serve them as they had expected. For example "the internet is very slow... the curtains are not completely sealed... there is no computer screen... the amplifiers are not intact".

\section{B. Staff development}

As part of the national ICT program, the college offered educators an abundance of courses and various instructional seminars, in order for them to be able to use different technologies in teaching in an educated way. Throughout these educational programs, the educators found that some of the ICT applications were actually suitable for the courses they teach, such as using a blog or a shared forum as well as giving the students online assignments. It was evident that educators' staff development constituted one of the most significant components for implementing the program, as one of the educators described it, "The multiple offers to participate in different educational programs enable acquisition of use of technological tools (interactive whiteboard, tablet) accompanied by support". 
Nonetheless, it was evident from the educators' words that the differences between educators and between the courses exist and require different ways of instruction and differential treatment, for example, "The summer workshops were excellent, but in the end I felt flooded and at times it was preferable not to conduct everything at once. Perhaps thinking about tracks or accommodation to the workshop's discipline is needed, so that the tools will be relevant to educators who participate in the workshop". "I feel flooded with all kinds of new technologies and it is difficult to filter them".

\section{The organizational climate at the college}

It is evident from educators' words that there is a policy and a clear declaration that is directed toward the use of technology in teaching. Educators are required to integrate technological tools into their work. As one of the teacher educators said, thanks to "the wind that blows both ideologically and practically and creates technological visibility" the teacher educator integrates technology. Educators testify that there is a demand on behalf of the college management to use Moodle in the course websites in a fluent and efficient way. Apparently, many educators feel responsible and obliged towards the organization and try to operate this way. This can be seen in their responses: "Unfortunately, I am not particularly knowledgeable in the existing technologies, but I do try to learn them and implement them"... "If there will be a demand and training and positivity for an educational program in the field, we will be forced to develop technological involvement. I will be happy". One of the educators explains his willingness and dedication to blend in: "It was decided that my course be ICT and so I was forced to deal with the course in the best possible way". The educators also feel a need to communicate with their students in effective ways, by sending and receiving messages, as part of the shift in perception. Educators are thankful for the widespread support within a relaxed and enabling environment, as well as for the assistance they receive from the ICT staff and from their colleagues.

Furthermore, the educators' responses reveal a critical attitude toward implementing technology without questioning it beforehand. As one of the educators explains: "I think that we should allow educators to use technological tools that they feel comfortable with (not just in a technical and practical way) but also in terms of value and personal customization. The insertion of new technologies always need to be accompanied by a viewing of the problematic issues and disadvantages of every technological tool. In the end what is important is that the learning will be significant and effective; innovative technology does not always promise this result".

\section{Required knowledge}

Educators see advanced technology as a means for improving their teaching practices. They acknowledge the importance of implementing innovative ICT in teaching and its potential in advancing learning, as one teacher educator explained: "We need to move forward... we must be taught how to use technology so that the students will be able to use classrooms in which they will learn with the technology". Another teacher educator explained in detail: "I think that there is a difference between the technologies and it is impossible to include all of them under one label. I, for example, really like using Moodle and YouTube but do not like using social websites, blogs, or iPads. Thus, it really depends on the nature of the technology as well as the character of the course and the learning material".

However, many of the educators report a lack of satisfactory technological knowledge. Educators describe this: "My lack of personal familiarity with diverse technologies", "A lack of satisfactory control". There are educators who attribute the lack of integration of technology into teaching to the lack of connectedness with the content of the courses they teach, the character of the course. There are educators who attribute this to a lack of pedagogic understanding, "A lack of practical knowledge in the use of different tools"; and there are educators who attribute the lack of integra- 
Integrating ICT in Teacher Colleges - A Change Process

tion to the personal viewpoints that the technology tools create fears in them or lack of faith in technology's ability to improve the learning.

\section{E. Time}

One of the most prominent factors that were reported by educators is time. From the teacher educator's point of view, there is a lack of time to become updated and practice different technologies. The technologies' urgent changes and the constant lack of time and energy available for investing in the teaching quite often creates a justified reason not to use technologies. There are educators who see the adoption of ICT as a process that requires time to learn and implement: "The rate of development of the tools is enormous and it takes time to learn them and understand how they can be implemented in teaching". Other comments stressed the heavy workload, such as obligations to their teaching duties or their commitment to their students. Such comments were as follows: "There is no time left for becoming familiar with and practicing the innovative technologies", "the developments occur very quickly and they are complex, I cannot, with my heavy work load, also become familiar with a new technology every year" or as one of the educators puts it: "I invest the best of my time in improving frontal courses". From the point of view of the student's learning, there are those who see the use of technologies as stealing time from the lessons or that there are students who have difficulty and there is no time to teach them.

\section{F. Motivation}

Many educators reported having curiosity, love, and interest in the field of media. The desire to progress and renew is expressed by educators in a very strong way. They see ICTs as an opportunity to improve the students' learning by means of using new technological tools. Educators reported the following: "Faith that this is the right thing and the college's requirement", "the desire not to stay behind", "to step forward with progress. I believe that technologies can motivate real change in the pedagogy", "I use innovative technologies when there is content-based justification and not as a fashion statement".

There are educators who do not have the desire to invest, as one of the educators declares openly: "The need for a great deal of investment in learning them, a very limited position scope that does not justify such an investment".

This and more, an analysis of questions and answers even teaches us that most of the educators are aware of the power of ICT in the educational system and the needs of the student who is undergoing training in his B.A. or M.A. degree. Therefore, they direct the teaching act towards change with the help of courses that integrate innovative technological tools. This finding is expressed in different magnitudes, as was said in expressions such as "the understanding that technology is based as part of real life as both a means and a tool that creates reality - I have a need for becoming acquainted with it and using it"... "I feel like a spearhead"... "Technology is the present need and I do not wish to have a student leave without the ability to use new technological tools".

\section{Discussion and Conclusions}

In recent years, there is a growing demand in universities and colleges for the use of technology to support academic learning needs (Lambert et al., 2014). Lecturers in teachers colleges, especially, need to supply the learners with knowledge that combines technology, pedagogy, and content, in order for these learners to be able to keep up with the pace of technological development in the course of their future work. The current research examined the systemic and personal factors that influence educators' work in an ICT environment. In the research, a SEM path analysis was performed, which enables a complex picture to be viewed both holistically and realistically. 
The analysis shows that the use of advanced technology tools constitutes a central factor in predicting student training in a technologically integrated ICT environment. According to the findings, student educators' control of ICT tools in their work is a powerful means for facilitating the technological-pedagogic change in the college, more than personal feelings, ICT culture, and the availability and technological-pedagogic support at the college. These findings strengthen the argument that the teacher's knowledge is a decisive factor in the change processes in the educational institution (Collinson, et al., 2009). Control of ICT tools divides into two levels. The first level is the level of assimilation, where the use of technological tools is for management needs and personal data collection, and the second level is the transformation level, where the use of technological tools is for cooperative and knowledge-structuring needs. According to the findings, most of the educators are at the assimilation level, and very few at the transformation level. As a result, it may be that educators are unable to guide students in the advanced technology environment. Therefore, very few of them report that while training students, they use strategies of performing cooperative online tasks, conduct event analyses using ICT, or employ technological tools, such as virtualizations, games, concept mapping, social networks, mobile phones and synchronous meetings. These findings complement a previous study, which found that the assimilation stage and conversion stage are two separate stages; however, they are both essential to adopting advanced technology among educators (MacCallum et al., 2014). This research points out the complexity entailed in instruction that integrates advanced technology tools and requires educators to be able to combine diverse digital technologies with skills of the $21^{\text {st }}$ century. These skills include development of creativity and innovation, critical thinking and problem-solving, and skills of communication and partnership (Partnership for 21st Century Skill, 2013). Despite the fact that it appears that the expected change has not yet occurred, as predicted in the literature (Goldstein et al., 2011; Zeichner \& Barth, 2013), it is apparent that there is a positive trend towards developing an innovative learning environment for students, both in emphasizing the use of research strategies during teaching-learning and in management of continuous learning on Moodle. In light of the findings, one may say that a teacher-educator training a student for working in education and instruction in the $21^{\text {st }}$ century, needs to be able to control the skills his students need to know himself, and at the same time provide them with opportunities for innovative learning and improving the quality of teaching.

Educators' responses to the open-ended questions complete the picture. It is evident from these responses that they are aware of the technological changes taking place in the educational system in general, and in the college in particular, and are focusing on adjusting their personal and professional perspectives. From the systemic aspect, educators bring to light three conditions that influence the integration of advanced technologies in their teaching: 1. Resources; 2. Staff development; 3. Organizational climate. From the personal process aspect, educators brought to light three factors that influence their teaching in an ICT environment: 1. Knowledge; 2. Time; 3. Motivation. These findings support the framework of factors that are involved in integrating technology into the college of education, according to Granston (2004). In terms of the initial environmental factors, it is apparent that educators mention all the necessary and critical conditions in order to succeed in implementing advanced technologies. However, in terms of secondary factors, the current research findings contribute another aspect. According to Granston (2004), in a successful integration of technologies in a college for education, educators constitute a model for their students if their viewpoints regarding integration of ICT are positive, instruction is performed for the student, and an experiential field for the student exists. The findings from the qualitative analysis did not show interpersonal characteristics that exist between the teacher educator and the students, but rather their intrapersonal characteristics, which express internal processes of change that are tested and designed anew, the teacher educator's knowledge, which includes the very positive attitudes towards integration, and in addition, the importance of educated implementation of technologies in teaching. Creating a connection between educators' different types of 
Integrating ICT in Teacher Colleges - A Change Process

Technological, Pedagogic And Content Knowledge (TPACK), makes innovative integration processes of technological tools more efficient, in this way advancing innovative and constructivist learning (Amirault, 2012; Koehler \& Mishra, 2009; Zeichner \& Barth, 2013). At this stage, it appears that educators' knowledge is not ready for integration. Additionally, the time factor constitutes one of the prominent factors in the change process that the teacher educator undergoes. It represents the efficiency that the teacher educator strives for in order to succeed. Often, the time factor is seen as negative in relation to the integration of technologies in teaching. Technology makes the process difficult, because it requires time for internalization and learning, and in this way, can delay the teaching and learning process (Avidov-Ungar \& Shmir-Inbal, 2013). Thus, the motivation factor has a significant influence on the integration of technology in teaching. Motivation is considered in the research literature as a central factor that encourages or delays the individual's performance, while the environmental variables contribute to it (Horizon Report, 2014). On the one hand, one can sense, from many educators' words, a strong desire to integrate technology, out of ideology, interest, and pleasure. On the other hand, other educators demonstrate a lack of interest in investing effort to learn the technologies, due to a lack of remuneration / compensation. According to Rogers (2003), workers who adopt innovations into the organization tend to operate out of internal motivation, in contrast to workers who delay and who are afraid and need external environmental stimulations. One can learn from this that currently the college is in a place where most of the educators are involved in the change process; therefore, it is appropriate that we take it a step further and advance the integration of technology in teaching in the college as an organization, out of a systemic vision that emphasizes the personal-professional development of the teacher educator.

Following the research findings, we recommend to develop digital-pedagogic literacy among educators adapted to personal needs and abilities, while learning in peer communities that are directed toward the educational field. In addition, it is recommended to integrate an intra-college involvement program that is gradual and long-term, adapted to the needs and goals of all persons who attend the college. This program will advance the field of innovative learning environments and the development of $21^{\text {st }}$ century skills. For future research, it is recommended to conduct a follow-up study after a period of one year and examine the changes that occurred with educators. Furthermore, we advise that future research include a comparison of various teachers colleges that have joined the National ICT Program, and elaborate upon the significance and meaning of the differences between them.

\section{References}

Alexander, S. (2006). Rethinking curriculum: Achieving qualitatively different outcomes using information technologies. Research and Practice in Technology Enhanced Learning 1(2), 157-161.

Amirault, R. J. (2012). Distance learning in the 21st century university. The Quarterly Review of Distance Education, 13(4), 253-265.

Anderson, R. (2008). Implications of the information and knowledge society for education. In J. Voogt, \& G. Knezek (Eds.), International handbook of information technology in primary and secondary education (pp. 5-22). NY: Springer.

Arbuckle, J. L. (2009). AMOS 18.0 User's Guide. Chicago: SPSS Inc.

Avidov-Ungar, O., \& Shmir-Inbal, T. (2013). Empowerment patterns of leaders in ICT and school strengths following the implementation of national ICT reform. Journal of Information Technology Education: Research, 12, 141-158. Retrieved from http://www.informingscience.org/Publications/1865

Barron, L. C., \& Goldman, E. S. (1994). Integrating technology with teacher preparation. In B. Means (Ed.), Technology and education reform (pp. 81-110). San Francisco, CA: Jossey-Bass Publishers. 
Bates, T. (2010). The strategic management of e-learning in universities and colleges. In J. Sanchez \& K. Zhang (Eds.), Proceedings of World Conference on E-Learning Corporate, Government, Healthcare, and Higher Education (E-LEARN) 2010. Chesapeake, VA: AACE. Retrieved February 19, 2014, from http://www.editlib org/p/35977

Blunch, N. J. (2008). Introduction to structural equation modelling using SPSS and AMOS. SAGE Publications

Bonk, C. J. (2010). For openers: How technology is changing school. Educational Leadership, 67(7), 6065.

Bower, M., Hedberg, J. G., \& Kuswara, A. (2010). A framework for Web 2 learning design. Educational Media International, 47(3), 177-198.

Bransford, J., Darling-Hammond. L. \& LePage, P. (2005). Chapter one: Introduction. In L. DarlingHammond \& J. Bransford (Eds), Preparing teachers for a changing world: What teachers should learn and be able to do, (pp.1-39). San-Francisco, CA: Jossey-Bass

Byrne, B. M. (2010). Structural equation modeling with AMOS: Basic concepts, applications, and programming (2nd ed.). New York: Routledge Academic.

Collinson, V., Kozina, E., Lin, Y. K., Ling, L., Matheson, I., Newcombe, L., \& Zogla, I. (2009). Professional development for teachers: A world of change. European Journal of Teacher Education, 32(1), $3-19$.

Connelly, F. M., Clandinin, J. D., \& He, M. F. (1997). Teachers' personal practical knowledge on the professional knowledge landscape. Teaching and Teacher Education, 13(7), 665-674.

Desimone, L. M. (2009). Improving impact studies of teachers' professional development: Toward better conceptualizations and measures. Educational Researcher, 38(3), 181-199.

Drexler, W., Baralt, A., \& Dawson. K. (2008). The Teach Web 2.0 Consortium: A tool to promote educational social networking and Web 2.0 use among educators. Educational Media International, 45, 271283.

Eckert, S. A. (2013). What do teaching qualifications mean in urban schools? A mixed-methods study of teacher preparation and qualification. Journal of Teacher Education. Retrieved January 22, 2014, from http://jte.sagepub.com/content/64/1/75

Ertmer, P. A., \& Ottenbreit-Leftwich, A. T. (2010). Teacher technology change: How knowledge, confidence, beliefs, and culture intersect. Journal of Research on Technology in Education, 42(3), 255-284.

Frank, K. A. (1998). Quantitative methods for studying social context in multilevels and through interpersonal relations. In P. D. Pearson \& A. Iran-Nejad (Eds.), Review of Research in Education, 23, 171216). Washington, DC: American Educational Research Association.

Fullan, M. (2007). The new meaning of educational change (4th ed.). New York: Teachers College Press.

Fullan, M., \& Donnelly, K. (2013). Alive in the swamp: Assessing digital innovations in education. London: NESTA; New York: New Schools Venture Fund.

Goldstein, O., Waldman, N., Tesler, B., Forkosh-Baruch, A., Shonfeld, M., Mor, N., Heilweil, I., Zelkovitz., Z., Zidan, W., \& Kozminsky, L. (2011). The current state of pre-service teachers training for ICT based teaching in Israel: 2008-2009. Proceedings of Global TIME: Global Conference on Technology, Innovation, Media \& Education, AACE.

Granston, N. C. (2004). Technology and teacher training: The systematic design and development of a framework for integrating technology into Jamaica's teacher training programs. A dissertation submitted in partial fulfillment of the requirements for the degree of Doctor of Philosophy. Department of Secondary Education. College of Education. University of South Florida.

Guskey, T. R. (2002). Professional development and teacher change. Teachers and Teaching: Theory and Practice, 8(3-4), 381-391. 
Integrating ICT in Teacher Colleges - A Change Process

Hargreaves, A., \& Fullan, M. (2013). The power of professional capital. With an investment in collaboration, teachers become nation builders. The Learning Foreword Journal, 34(3), 36-39.

Hong, H. Y., Scardamalia, M., \& Zhang, J. (2010). Knowledge Society Network: Toward a dynamic, sustained network for building knowledge. Canadian Journal of Learning and Technology, 36(1). Retrieved January 22, 2015, from http://www.cjlt.ca

Horizon Report. (2014). Higher Education Edition. NMC. Retrieved January 22, 2014, from http://www.nmc.org/publications/2014-horizon-report-higher-ed

Hoyle, R. H. (Ed.) 1995. Structural equation modeling. Thousand Oaks, CA: SAGE Publications.

Hoyle, R. H., \& Panter, A. T. (1995). Writing about structural equation models. In R. H. Hoyle, Structural equation modeling: Concepts, issues, and applications. Newbury Park, CA: Sage.

Ilomaki, L. (2008). The effects of ICT on school: Teachers' and students' perspectives. University of Torku, Finland. Retrieved January 18, 2015, from https://oa.doria.fi/bitstream/handle/10024/42311/B314.pdf?sequence=3

Jacobsen, M., \& Lock, J. (2004). Technology and teacher education for a knowledge era. Mentoring for student futures, not our past. Journal of Technology and Teacher Education, 12(1), 75-100.

Johnson, L., Levine, A., Scott, C., Smith, R., \& Stone, S. (2009). The Horizon Report: 2009 economic development edition. Austin, Texas: The New Media Consortium.

Kimble, C. (1999). The impact of technology on learning. Making sense of the research. Policy Brief. MidContinental Regional Educational Laboratory.

Koehler, M. J., \& Mishra, P. (2009). What is technological pedagogical content knowledge? Contemporary Issues in Technology and Teacher Education, 9(1). Retrieved December 12, 2014, from http://www.citejournal.org/vol9/iss1/general/article1.cfm

Kozma, R. B. (2010). ICT policies and educational transformation. A UNESCO publication.

Lakoff, G., \& Johnson, M. (1980). Metaphors we live by. Chicago and London: University of Chicago Press.

Lambert, C., Erickson, L., Alhramelah, A., Rhoton, D., Lindbeck, R. \& Sammons, D. (2014).Technology and adult students in higher education: A review of the literature. Issues and Trends in Educational Technology, 2(1). University of Arizona Libraries.

Leavy, A. M., McSorley, F. A., \& Boté, L. A. (2007). An examination of what metaphor construction reveals about the evolution of preservice teachers' beliefs about teaching and learning. Teaching and Teacher Education, 23(7), 1217-1233

Linn, M. C. (2005). WISE design for lifelong learning - pivotal cases. In P. Gardenfors \& P. Johansson (Eds.), Cognition, education and communication technology (pp. 223-256). Mahwah, NJ: Lawrence Erlbaum Associates.

Luque, M. L. (2003). The role of domain-specific knowledge in intentional conceptual change. In G. M. Sinatra \& P. R. Pintrich (Eds.), Intentional conceptual change (pp. 133-170). Mahwah, NJ: Lawrence Erlbaum Associates,

MacCallum, K., Jeffrey, L., \& Kinshuk, H. R. (2014). Factors impacting teachers' adoption of mobile learning. Journal of Information Technology Education: Research, 13, 141-162. Retrieved from http://www.jite.org/documents/Vol13/JITEv13ResearchP141-162MacCallum0455.pdf

Martinez, M. A., Sauleda, N., \& Huber G. L. (2001). Metaphors as blueprints of thinking about teaching and learning. Teaching and Teacher Education, 17(8), 965-977.

Martinovic, D., \& Zhang, Z. (2012). Situating ICT in the teacher education program Overcoming challenges, fulfilling expectations. Teaching and Teacher Education, 28(3), 461-569.

Maskit, D. (2013). Pedagogical changes: Initiators, causes, dominant factors - A teacher's view. The International Journal of Pedagogy and Curriculum, 19(3), 89-107. 
McKenzie, B. K., Kirby, E., \& Mims, N. G. (1996). Preparing for the future with technology: Extending past the classroom. Journal of Information Technology for Teacher Education, 5(1-2), 83-92.

Ministry of Education, Israel. (2011). Adapting teacher training colleges to 21st century education (Hebrew). Retrieved December 12, 2014, from http://cms.education.gov.il/NR/rdonlyres/0B08B8D7E387-4E58-9DCF-1485ED7CCE20/158440/21CenturySkilsJuly2011.pdf

Ministry of Education, Israel. (2013). National project for adaptation of the education system to the 21st century: Vision and rationale (Hebrew). Retrieved December 12, 2014, from http://cms.education.gov.il/educationcms/units/madatech/ictineducation/

Muijs, D., \& Lindsay, G. (2008). Where are we at? An empirical study of levels and methods of evaluating continuing professional development. British Educational Research Journal, 34(2), 195-211.

Mumtaz, S. (2000). Factors affecting teachers' use of information and communications technology: A review of the literature. Journal of Information Technology for Teacher Education, 9(3), 319-342.

Partnership for 21st Century Skill. (2013). A framework for 21st century learning. Retrieved February 21, 2014 from http://www.p21.org/overview

Pijl, S. J. (2009). What policymakers can do to make education inclusive? Educational Management Administration \& Leadership, 37(3), 366-377.

Reeves, T. C., \& Reeves, P. M. (2012). Designing online and blended learning. Melbourne: Acer Press.

Rizza, C. (2011). ICT and initial teacher education: National policies. OECD Education Working Papers, 61. OECD Publishing.

Rogers, E. M. (2003). Diffusion of Innovations (5th ed.) New York: Free Press.

Russell, J., Jane, G., \& Marshall, G. (2011). Use of a dual-target approach to achieving pedagogical change in schools. Presentation of a roundtable discussion of research in progress to the ICSEI Congress, Limassol, Cyprus, 4 - 7 January, 2011. Retrieved December 10, 2015 http://www.icsei.net/icsei2011/Full\%20Papers/0024.pdf

Sabana, A., Kocbekerb, B. N., \& Sabanc, A. (2007). Prospective teachers' conceptions of teaching and learning revealed through metaphor analysis. Learning and Instruction, 17(2), 123-139.

Salomon, G. (2001). Technology and education in the age of information. Zmora-Bitan (Hebrew).

Scardamalia, M., \& Bereiter, C. (1999). Schools as knowledge- building organizations. In D. Keating \& C. Hertzman (Eds.), Today's children, tomorrow's society: The developmental health and wealth of nations (pp.274-289). New York, NY: Guilford.

Solvie, P., \& Kloek, M. (2007). Using technology tools to engage students with multiple learning styles in a constructivist learning environment. Technology and Teacher Education, 7(2), 7-27.

Stake, R. E. (2006). Multiple case study analysis. New York: The Guilford Press.

Strauss, A., \& Corbin, J. (1990). Basics of qualitative research: Grounded theory procedures and techniques. Newbury Park, CA: Sage.

Surry, D. W. (2001). A model for integrating instructional technology into higher education. Proposal submitted to SIG: Instructional Technology.

Tee, M., \& Lee, S. (2011). From socialisation to internalisation: Cultivating technological pedagogical content knowledge through problem-based learning. Australasian Journal of Educational Technology, 27(1), 89-104.

Van Veen, K. \& Sleegers, P. (2006). How does it feel? Teachers' emotions in a context of change. Journal of Curriculum Studies, 38(1), 85-111.

Voogt, J. (2012). Are teachers ready to teach in the knowledge society? Considerations based on empirical findings. Jahrbuch Medienpädagogik, 9, 17-28. 
Zeichner, O., \& Barth, I. (2013). Helping teachers design effective online courses: A 4-pillar faculty development model. Sloan-C 6th Annual International Symposium on Emerging Technologies for Online Learning, Las Vegas.

Zhang, J. (2010). Technology-supported learning innovation in cultural contexts. Educational Technology Research and Development, 58(2), 229-243.

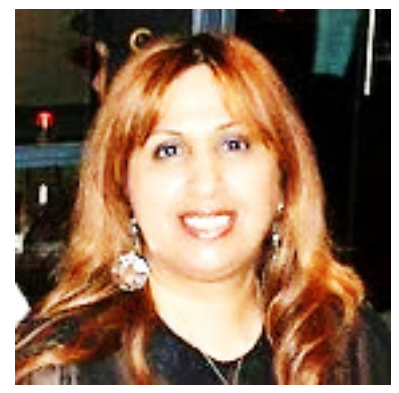

\section{Biographies}

Dr. Noga Magen-Nagar is the Vice Director of the M.Ed. Department of Teaching, Learning and Mentoring and senior lecturer at the Gordon Academic College of Education in Israel. She is also the evaluator and academic advisor for the national ICT program in the Department of Science and Technology at the Ministry of Education. Her areas of expertise and research focus on integrating ICT in education, quality of teaching, innovative learning environment, and evaluation in education.

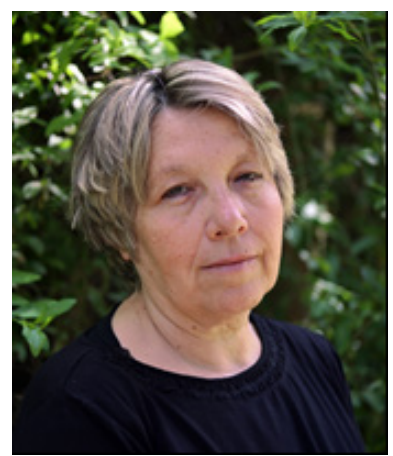

Prof. Ditza Maskit is a senior lecturer at Gordon College of Education, Haifa, Israel, and a member of the authoroty unit at the College. The editor of the college academic journal "Rav-Gvanim". Serves as the coordinator of the Professional Development Schools Network (PDS) for teachers education colleges in Israel at the MOFET Center for Research and Development Programs in teacher education colleges. Her research focuses mainly on educational change, teachers' professional development, induction and novices' world. She has published articles on these topics, and serves as a reviewer in leading academic journals in teacher education. 